ISSN: 00489697

doi: 10.1016/j.scitotenv.2013.04.043

\title{
POTENTIAL ADVERSE HEALTH EFFECTS OF PERSISTENT ORGANIC POLLUTANTS ON SEA TURTLES: EVIDENCES FROM A CROSS-SECTIONAL STUDY ON CAPE VERDE LOGGERHEAD SEA TURTLES
}

\author{
Camacho, M. ${ }^{a}$, Luzardo, O.P. ${ }^{b}$, Boada, L.D. ${ }^{\text {, }}$ López Jurado, L.F. ${ }^{c}$, Medina, M. ${ }^{c}$, Zumbado, M. ${ }^{b}$, \\ Orós, J. ${ }^{\mathrm{a}}$
}

a Veterinary Faculty, University of Las Palmas de Gran Canaria, Arucas, Las Palmas, Spain.

b Toxicology Unit, Department of Clinical Sciences, University of Las Palmas de Gran Canaria, Plaza Dr. Pasteur s/n (trasera Hospital Insular), 35016 Las Palmas de Gran Canaria, Spain.

c Cabo Verde Natura 2000, Sal Rei, Boa Vista, Cape Verde.

\begin{abstract}
The Cape Verde nesting population of loggerhead sea turtles (Caretta caretta) is the third largest population of this species in the world. For conservation purposes, it is essential to determine how these reptiles respond to different types of anthropogenic contaminants. We evaluated the presence of organochlorine pesticides (OCPs), polychlorinated biphenyls (PCBs), and polycyclic aromatic hydrocarbons (PAHs) in the plasma of adult nesting loggerheads from Boa Vista Island, Cape Verde, and studied the effects of the contaminants on the health status of the turtles using hematological and biochemical parameters. All turtles had detectable levels of non-dioxin like PCBs, whereas dioxin-like congeners (DL-PCBs) were detected in only $30 \%$ of the turtles. Packed cell volume decreased with higher concentrations of $\mathrm{PCBs}$, which suggests that $\mathrm{PCB}$ exposure could result in anemia in sea turtles. In addition, a negative association between some OCPs and white blood cells (WBC) and thrombocyte estimate was noted. The DDT-metabolite, $p, p^{\prime}-D D E$ was negatively correlated with the $\mathrm{Na} / \mathrm{K}$ ratio and, additionally, a number of correlations between certain PAHs and electrolyte balances were found, which suggest that exposure to these environmental contaminants could affect the kidneys and salt glands in sea turtles. Additionally, several correlations were observed between these environmental pollutants (OCPS and PAHs) and enzyme activity (GGT, ALT, ALP and amylase) and serum protein levels, pointing to the possibility that these contaminants could induce adverse metabolic effects in sea turtles. Our results indicate that anthropogenic pollutants are present in the Cape Verde loggerhead turtle nesting population and could exert negative effects on several health parameters. Because of the importance of this loggerhead nesting population, protective regulations at national and international levels as well as international action are necessary for assuring the conservation of this population.
\end{abstract}

